\title{
Sildenafil does not affect the proliferation of human lymphocytes in the in vitro transplant model
}

\author{
Beata Kaleta ${ }^{\varpi}$ and Agnieszka Boguska \\ Department of Clinical Immunology, Transplantation Institute, Medical University of Warsaw, Warsaw, Poland
}

\begin{abstract}
Sildenafil is used in the treatment of erectile dysfunction and pulmonary arterial hypertension. Numerous studies revealed beneficial effects of its use in renal, liver, heart and bone marrow transplant recipients. Some reports suggested that the drug modulates the function of the immune system, however, its influence on antigen-induced proliferation of lymphocytes remains unknown. Thus, the aim of the study was to investigate the effects of sildenafil on human peripheral blood mononuclear cells (PBMCs) proliferation in a mixed lymphocyte reaction. It was demonstrated that the drug did not affect auto- and alloantigen-induced proliferation of PBMCs and showed no cytotoxic effect.
\end{abstract}

Key words: mixed lymphocyte reaction, PDE5 inhibitor; peripheral blood mononuclear cells; sildenafil

Received: 18 June, 2018; revised: 21 December, 2018; accepted: 04 January, 2019; available on-line: 28 February, 2019

e-mail: kaletabeata1@gmail.com

Acknowledgements of Financial Support: research supported by intramural funds from the Medical University of Warsaw [1MG/N/2017].

Abbreviations: ED, erectile dysfunction; GMP, guanosine 3,5-monophospahate; IL, interleukin; MLR, mixed lymphocyte reaction; $\mathrm{NO}$, nitric oxide; $\mathrm{PAH}$, pulmonary arterial hypertension; PBMCs, peripheral blood mononuclear cells; PDE5, type 5 phosphodiesterase; TNF-a, tumor necrosis factor alpha

\section{INTRODUCTION}

Sildenafil (5-[2-ethoxy-5-(4-methylpiperazin-1-ylsulfonyl)phenyl]-1-methyl-3-propyl-1,6-dihydro-7H-pyrazolo[4,3-d]pyrimidin-7-one; $\mathrm{C}_{22} \mathrm{H}_{30} \mathrm{~N}_{6} \mathrm{O}_{4} \mathrm{~S}$ ) is a selective inhibitor of type 5 phosphodiesterase (PDE5), a major enzyme hydrolyzing cyclic guanosine 3,5-monophosphate (cGMP) to GMP. cGMP is expressed in cardiomyocytes, vessel and ureteral smooth muscle cells, endothelial, epithelial, myometrial and immune cells (Nichols et al., 2002; Kukreja et al., 2005). As a second messenger, cGMP mediates the action of nitric oxide (NO), regulating a broad array of physiological processes (Dhayade et al., 2016). By blocking the breakdown of cGMP, sildenafil acts to prolong the effects of this cyclic monophosphate.

Sildenafil is the first line therapy of erectile dysfunction (ED) and pulmonary arterial hypertension (PAH) (Essayan, 2001). ED is common in male patients with renal diseases and in patients after kidney transplantation, in which the drug is used effectively and safely (Zhang et al., 2005; Sharma et al., 2006). A growing body of evidence shows that sildenafil exerts immunomodulatory effects, however, most studies were performed in animal models (Serafini et al., 2006; Szczypka \& Obmnska-Mrukowicz, 2010; Pifarre et al., 2011; 2014). Not much information is available about the impact of sildenafil on the human immune system. Our recent studies demonstrated for the first time that sildenafil downregulates natural killer cells activity (Boguska et al., 2018) and osteopontin (Kaleta \& Boguska, 2017) production in human peripheral blood mononuclear cells (PBMCs). Moreover, we showed that sildenafil upregulates tumor necrosis alpha $(\mathrm{TNF}-\alpha)$ production but has no effect on interleukin (IL)-6 and IL-1 $\beta$ synthesis (Kaleta et al., 2019), as well as on phagocytic activity of granulocytes (Boguska et al., 2018). There are reports suggesting that selective PDE5 inhibitors affect human endothelial, bone marrow and cancer cells proliferation (Erdogan et al., 2007; Li et al., 2007; Wang et al., 2008; He et al., 2017), however, the influence of sildenafil on antigen-induced proliferation of lymphocytes has not been studied up to date.

To address this subject, the aim of the study was to investigate the effects of sildenafil on healthy human PBMCs proliferation in a mixed lymphocyte reaction (MLR). MLR is an efficient in vitro model for studying T-cell activation and proliferation (Potter \& Moore, 1977).

\section{MATERIALS AND METHODS}

Isolation of peripheral blood mononuclear cells and mixed lymphocyte reaction. 30 healthy blood donors participated in the study. PBMCs were isolated from heparinized blood by centrifugation on Histopaque-1077 (Sigma, St. Louis, USA). PBMCs were resuspended in Parker's medium (Biomed, Lublin, Poland) supplemented with $2 \mathrm{mM}$ L-glutamine, 0.23\% Hepes (both from Sigma, St. Louis, USA), $0.1 \mathrm{mg} / \mathrm{ml}$ gentamycin (KRKA, Novo Mesto, Slovenia) and 10\% fetal bovine serum (FBS, Gibco, Darmstadt, Germany). Half of the isolated PBMCs were inactivated by gamma-irradiation for $90 \mathrm{~min}$. Sildenafil citrate (Sigma, St. Louis, USA) was dissolved in $0.9 \%$ sodium chloride $(0.9 \% \mathrm{NaCl}$, Fresenius Kabi, Bad Homburg, Germany) to the initial concentration of $100 \mu \mathrm{g} / \mathrm{mL}$.

The mixed lymphocyte reaction (MLR) was performed by seeding $1 \times 10^{5}$ responder PBMCs into the wells of a 96-well plate, and $1 \times 10^{5}$ irradiated (stimulatory) PBMCs in the following combinations:

$\mathrm{AA}_{\mathrm{ir}} \mathrm{BB}_{\mathrm{ir}} \mathrm{ABir} \mathrm{BA}_{\mathrm{ir}}$ donor 1 and 2

$\mathrm{AA}_{\mathrm{ir}} \mathrm{BB}_{\mathrm{ir}} \mathrm{AB}_{\mathrm{ir}} \mathrm{BA}_{\mathrm{ir}}$ donor 3 and 4 , etc.

A, B - PBMCs (responding cells), $A_{i r}, B_{i r}-$ irradiated PBMCs (stimulating cells)

Cells were co-cultured with sildenafil at concentrations of $0.06 \mu \mathrm{M}, 0.6 \mu \mathrm{M}$ and $6 \mu \mathrm{M}$. Drug concentrations were selected on the basis of the near therapy doses, according to their pharmacokinetics $\left(\mathrm{C}_{\max }\right.$ and area un- 
der the time-concentration curve, AUC). $0.6 \mu \mathrm{M}$ is an average serum level of sildenafil after a single $100 \mathrm{mg}$ oral administration (Nichols et al., 2002). $0.06 \mu \mathrm{M}$ and $6 \mu \mathrm{M}$ are 10 -fold lower and 10 -fold higher, respectively. The concentration of $6 \mu \mathrm{M}$ was used to test the potential toxic effects. Control cultures contained equivalent volumes of the medium.

PBMCs were cultured for 5 days at $37^{\circ} \mathrm{C}$ in a humidified atmosphere with $5 \% \mathrm{CO}_{2}$. After 5 days, PBMCs were pulsed with $1 \mu \mathrm{Ci} /$ well of ${ }^{3} \mathrm{H}$-thymidine $(113 \mathrm{Ci} /$ nmol, NEN, Boston, USA) for the last $18 \mathrm{~h}$ of the incubation and harvested. The amount of ${ }^{3} \mathrm{H}$-thymidine incorporated into the cells was measured using the scintillation counter (Wallac, PerkinElmer, Boston, USA), giving the level of radioactivity as 'Corrected Counts per Minute' (CCPM). Experiments were performed in triplicates.

Cell viability assay. PBMCs viability was examined using trypan blue staining. After 5 days of culture, PBMCs were collected and stained with $0.4 \%$ trypan blue. The number of total and dead cells was counted using a hemocytometer. Values were expressed as a percentage of control culture viability $(100 \%)$.

Statistical analysis. All analyses were performed with Statistica version 12.5. The results were expressed as mean \pm standard deviation (SD). After testing all the data for normality (Shapiro-Wilk test), one-way ANOVA was used to compare values obtained with or without sildenafil treatment. A probability value of $p<0.05$ with a $95 \%$ confidence interval was considered to indicate a statistically significant difference.

The study was approved by the Ethics Committee of the Medical University of Warsaw (No. KB/164/2017) and all subjects provided their written informed consent. The procedures followed were in accordance with the Helsinki Declaration of 1975, as revised in 2000.

\section{RESULTS}

As expected, the addition of allogeneic irradiated PBMCs from one donor to responding PBMCs from unrelated second donor resulted in an increase in lymphocytes proliferation $(\phi<0.01$ in comparison to the autostimulated variants). Sildenafil at all tested concentrations $(0.06,0.6$ and $6 \mu \mathrm{M})$ did not affect auto- and alloantigen-induced proliferation of PBMCs $(p>0.05)$ (Fig. 1) as well as PBMCs viability (percentage of viable cells was $96.5 \% \pm 1.9 \%$ [range: 96-97\%]) ( $p>0.05)$ (Fig. 2).

\section{DISCUSSION}

Despite the fact that PDE5 inhibitors showed efficacy and safety, it is important to know whether they can affect the human immune system as they are used in patients after organ transplantation. Thus, studies in transplant settings, including in vitro transplant models, as presented in the current work, are required. The results of our analysis demonstrated for the first time that sildenafil has no significant effects on the auto- and alloantigen-induced proliferation of human PBMCs and does not affect the cells viability.

As mentioned above, sildenafil is used in patients with ED and PAH (Essayan, 2001; Boswell-Smith et al., 2006). ED is common in male patients with renal diseases and in patients after kidney transplantation, in which the drug is effective and safe (Sharma et al., 2006). In addition, multiple studies revealed beneficial effects of sildenafil use in renal, liver, heart and bone marrow

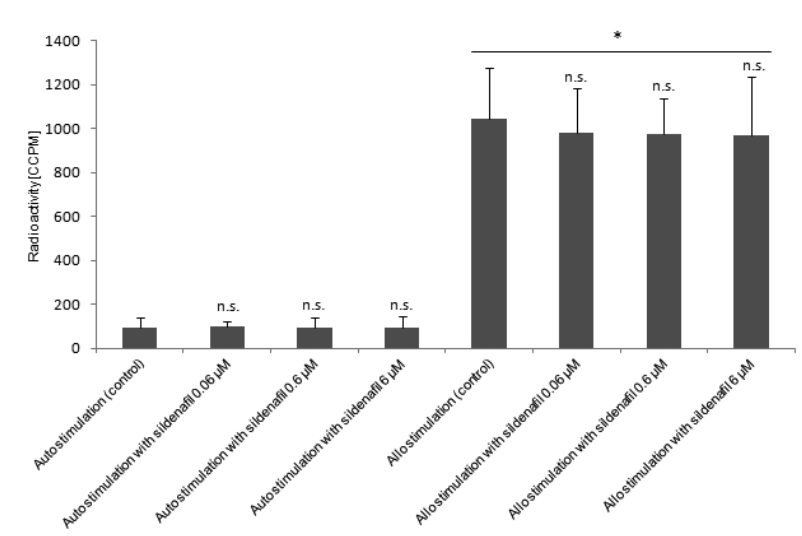

Figure 1. Effect of sildenafil $(0.06,0.6$ and $6 \mu \mathrm{M})$ on peripheral blood mononuclear cells (PBMCs) proliferation in a mixed lymphocyte reaction (MLR).

The proliferation of lymphocytes cultured with irradiated PBMCs from the same donor (autostimulation) and from the second unrelated donor (allostimulation) was examined on the DNA synthesis level by the measurements of ${ }^{3} \mathrm{H}$-thymidine incorporation. The results are presented as a level of radioactivity measured as 'Corrected Counts per Minute' (CCPM). Data are presented as mean \pm standard deviation of 30 experiments performed in triplicates, ${ }^{*}$ $p<0.01$ in comparison to autostimulated variants, n.s. $=$ not statistically significant.

transplant recipients (Russo et al., 2004; Zhang et al., 2005; Lledo-Garcia et al., 2007; De Santo et al., 2008; Boffini et al., 2009; Lansaponara et al., 2013; Singh et al., 2014). Moreover, accumulating data indicate that sildenafil can play an important role in the regulation of the immune system in animals (Serafini et al., 2006; Szczypka \& Obmnska-Mrukowicz, 2010; Pifarre et al., 2011; Pifarre et al., 2014). However, the data about its influence on human immune cells are limited. It was demonstrated that incubation of PBMCs isolated from myeloma and head and neck cancer patients with sildenafil restored CD4+ $T$ cells proliferation (Serafini et al., 2006). Another study (Pifarre et al., 2014) provided evidence that sildenafil enhances the ability of healthy human regulatory $\mathrm{T}$ cells (Tregs) to down-regulate the proliferation of the effector $\mathrm{T}$ cells (Teffs). He and colleagues (2017) revealed that sildenafil suppressed the proliferation of hemangioma endothelial cells (HemECs) in vitro. Further analyses confirmed that sildenafil inhibited the prolifera-

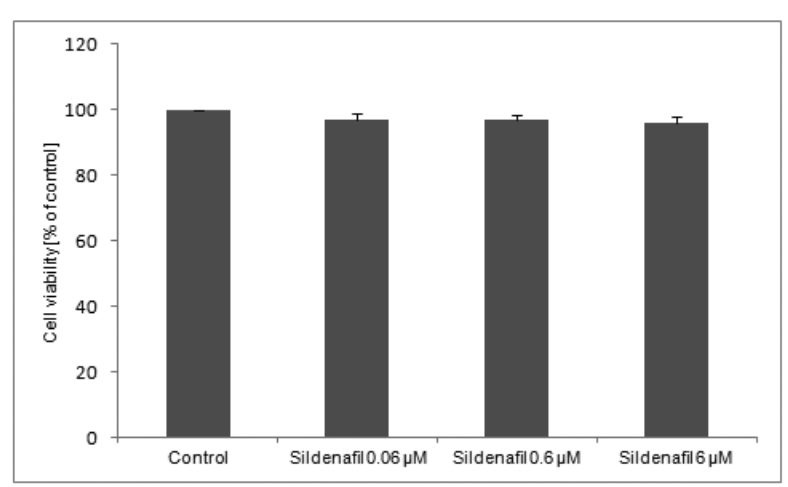

Figure 2. Effect of sildenafil $(0.06,0.6$ and $6 \mu \mathrm{M})$ on peripheral blood mononuclear cells (PBMCs) viability.

PBMCs were incubated with sildenafil for 5 days. Cell viability was measured using trypan blue staining. Results are expressed as the percent of control cells viability. Data are presented as mean \pm standard deviation for each sildenafil dose, $n=30$. 
tion of pulmonary artery smooth muscle cells (PASMCs) (Li et al., 2007; Wang et al., 2008). Erdogan and colleagues (2007) likewise demonstrated the antiproliferative effects of sildenafil on human endothelial cells. In contrast, Doganci et al. (2015) showed that the drug-induced proliferation of human umbilical vein endothelial cells (HUVECs). In another study, Santos and others (Santos et al., 2014) revealed that the treatment with sildenafil increased the proliferation of the subventricular zone (SVZ)-derived neural stem cells (NSCs).

Since PDE5 is expressed in human immune cells and sildenafil increases cGMP levels, we speculated that the drug, which is used in transplant recipients, could affect the proliferation of PBMCs. The present study, although on a limited number of participants, demonstrated that sildenafil had no significant effects on the auto- and alloantigen-induced proliferation of human lymphocytes in the in vitro transplant model. Based on the contradictory observations of previous authors and the results of the current study, we conclude that the effects of sildenafil on cellular proliferation are variable and dependent on the type of cells studied. Therefore, further functional studies are required to elucidate the potential mechanisms of immunomodulatory actions of this PDE5 inhibitor.

\section{Acknowledgements}

We thank Dr. Radosław Zagozdzon, the head of Department of Clinical Immunology, for helpful discussion and review of the manuscript.

\section{Conflicts of Interests}

None declared.

\section{REFERENCES}

Boffini M, Sansone F, Ceresa F, Ribezzo M, Patanè F, Comoglio C, Rinaldi M (2009) Role of oral sildenafil in thetreatment of right ventricular dysfunction after heart transplantation. Transplant Proc 41: 1353-1356. https://doi.org/10.1016/j.transproceed.2009.03.042

Boguska A, Kaleta B, Kniotek M, Górski A (2018) Sildenafil, a selective phosphodiesterase type 5 inhibitor, downregulates natural killer cells activity in healthy men in vitro. Acta Pol Pharm 1: 211-216

Boswell-Smith V, Spina D, Page CP (2006) Phosphodiesterase inhibitors. Br J Pharmacol 147: S252-S257. https://doi.org/10.1038/ si.bjp. 0706495

De Santo LS, Mastroianni C, Romano G, Amarelli C, Marra C, Maiello C, Galdieri N, Della Corte A, Cotrufo M, Caianiello G (2008). Role of sildenafil in acute posttransplant right ventricular dysfunction: successful experience in 13 consecutive patients. Transplant Proc 40: 2015-2018. https://doi.org/10.1016/j.transproceed.2008.05.055

Dhayade S, Kaesler S, Sinnberg T, Dobrowinski H, Peters S, Naumann U, Liu H, Hunger RE, Thunemann M, Biedermann T, Schittek B, Simon HU, Feil S, Feil R (2016). Sildenafil potentiates a cGMPdependent pathway to promote melanoma growth. Cell Rep 14: 2599-2610. https://doi.org/10.1016/j.celrep.2016.02.028

Doganci S, Yildirim V, Yesildal F, Erol G, Kadan M, Ozkan G, Avcu $\mathrm{F}$, Ozgurtas T (2015) Comparison of angiogenic and proliferative effects of three commonly used agents for pulmonary artery hypertension (sildenafil, iloprost, bosentan): is angiogenesis always beneficial? Eur Rev Med Pharmacol Sci 19: 1900-1906. PMID: 26044238

Erdogan A, Luedders DW, Muenz BM, Schaefer CA, Tillmanns H, Wiecha J, Kuhlmann CR (2007) Sildenafil inhibits the proliferation of cultured human endothelial cells. Int J Biomed Sci 3: 93-96. PMC3614625

Essayan DM (2001) Cyclic nucleotide phosphodiesterases. J Allergy Clin Immunol 108: 671-680. https://doi.org/10.1067/mai.2001.119555

He X, Liu Y, Li K, Yang A, Wang R, Liu S (2017) Sildenafil suppresses the proliferation and enhances the apoptosis of hemangioma endothelial cells. Exp Ther Med 13: 2645-2650. https://doi. org/10.3892/etm.2017.4306

Kaleta B, Boguska A, Borysowski J, Górski A (2019) Sildenafil upregulates tumor necrosis factor $\alpha$ production in peripheral blood mono- nuclear cells of healthy men - preliminary report. Acta Pol Pharm 1 : 123-128

Kaleta B, Boguska A (2017) Sildenafil, a phosphodiesterase type 5 inhibitor, downregulates osteopontin in human peripheral blood mononuclear cells. Arch Immunol Ther Exp (Warsz) 65: 347-353. https://doi.org/10.1007/s00005-017-0455-9

Kukreja RC, Salloum F, Das A, Ockaili R, Yin C, Bremer YA, Fisher PW, Wittkamp M, Hawkins J, Chou E, Kukreja AK, Wang X, Marwaha VR, Xi L (2005) Pharmacological preconditioning with sildenafil: basic mechanisms and clinical implications. Vascul Pharmacol 42: 219-232. https://doi.org/10.1016/j.vph.2005.02.010

Lasaponara F, Sedigh O, Pasquale G, Bosio A, Rolle L, Ceruti C, Timpano M, Negro CL, Paradiso M, Abbona A, Segoloni GP, Fontana D (2013) Phosphodiesterase type 5 inhibitor treatment for erectile dysfunction in patients with end-stage renal disease receiving dialysis or after renal transplantation. J Sex Med 10: 2798-2814. https://doi. org/10.1111/jsm.12038

Li B, Yang L, Shen J, Wang C, Jiang Z (2007) The antiproliferative effect of sildenafil on pulmonary artery smooth muscle cells is mediated via upregulation of mitogen-activated protein kinase phosphatase-1 and degradation of extracellular signal-regulated kinase 1/2 phosphorylation. Anesth Analg 105: 1034-1041. https://doi. org/10.1213/01.ane.0000278736.81133.26

Lledo-Garcia E, Rodriguez-Martinez D, Cabello-Benavente R, Moncada-Iribarren I, Tejedor-Jorge A, Dulin E, Hernandez-Fernandez C, Del Canizo-Lopez JF (2007) Sildenafil improves immediate posttransplant parameters in warm-ischemic kidney transplants: experimental study. Transplant Proc 39: 1354-1356. https://doi. org/10.1016/j.transproceed.2007.01.082

Nichols DJ, Muirhead GJ, Harness JA (2002) Pharmacokinetics of sildenafil after single oral doses in healthy male subjects: absolute bioavailability, food effects and dose proportionality. $\mathrm{Br}$ I Clin Pharmacol 53 (Suppl 1): 5S-12S. PMCID: PMC1874258

Pifarré P, Gutierrez-Mecinas M, Prado J, Usero L, Roura-Mir C, Giralt M, Hidalgo J, García A (2014) Phosphodiesterase 5 inhibition at disease onset prevents experimental autoimmune encephalomyelitis progression through immunoregulatory and neuroprotective actions. Exp Neurol 251: 58-71. https://doi.org/10.1016/j.expneurol.2013.10.021

Pifarre P, Prado J, Baltrons MA, Giralt M, Gabarro P, Feinstein DL, Hidalgo J, Garcia A (2011) Sildenafil (Viagra) ameliorates clinical symptoms and neuropathology in a mouse model of multiple sclerosis. Acta Neuropathol 121: 499-508. https://doi.org/10.1007/ sclerosis. Acta Neurop

Potter MR, Moore M (1977) Human mixed lymphocyte culture using separated lymphocyte populations. Immunology 32: 359-365. PMCID: PMC1445300

Russo D, Musone D, Alteri V, Cindolo L, Lanzillo B, Federico S, Andreucci VE (2004) Erectile dysfunction in kidney transplanted patients: efficacy of sildenafil. I Nephrol 17: 291-295. PMID: 15293531

Santos AI, Carreira BP, Nobre RJ, Carvalho CM, Araújo IM (2014) Stimulation of neural stem cell proliferation by inhibition of phosphodiesterase 5. Stem Cells Int 2014: 878397. https://doi. org/10.1155/2014/878397

Serafini P, Meckel K, Kelso M, Noonan K, Califano J, Koch W, Dolcetti L, Bronte V, Borrello I (2006) Phosphodiesterase-5 inhibition augments endogenous antitumor immunity by reducing myeloid-derived suppressor cell function. J Exp Med 203: 2691-2702. https:// doi.org/10.1084/jem.20061104

Sharma RK, Prasad N, Gupta A, Kapoor R (2006) Treatment of erectile dysfunction with sildenafil citrate in renal allograft recipients: a randomized, double-blind, placebocontrolled,crossover trial. Am J Kidney Dis 48: 128-133. https://doi.org/10.1053/j.ajkd.2006.04.061

Singh RK, Richmond ME, Zuckerman WA, Lee TM, Giblin TB, Rodriguez R, Chen JM, Addonizio LJ (2014) The use of oral sildenafil for management of right ventricular dysfunction after pediatric heart transplantation. Am J Transplant 14: 453-458. https://doi. org/10.1111/ajt.12552

Szczypka M, Obminska-Mrukowicz B (2010) Modulating effects of nonselective and selective phosphodiesterase inhibitors on lymphocyte subsets and humoral immune response in mice. Pharmacol Rep 62: 1148-1158. PMID: 21273672

Wang C, Wang J, Zhao L, Wang Y, Liu J, Shi L, Xu M, Wang C (2008) Sildenafil inhibits human pulmonary artery smooth muscle cell proliferation by decreasing capacitative $\mathrm{Ca}^{2+}$ entry. J Pharmacol Sci 108: 71-78. PMID: 18818482

Zhang Y, Guan DL, Ou TW, Wang Y, Chen X, Xing NZ, Zhang XD, Yang Y (2005) Sildenafil citrate treatment for erectile dysfunction after kidney transplantation. Transplant Proc 37: 2100-2103. https:// doi.org/10.1016/j.transproceed.2005.03.026 